See discussions, stats, and author profiles for this publication at: https://www.researchgate.net/publication/332118774

\title{
Psychometric and Rash Analysis of the UCLA Loneliness Scale - 16 in a Portuguese Sample of Older Adults
}

Article in Psychological Studies · June 2019

DOI: 10.1007/s12646-019-00483-5

CITATIONS

5

7 authors, including:

Bruno Faustino

University of Lisbon

51 PUBLICATIONS 120 CITATIONS

SEE PROFILE

Jorge Oliveira

Universidade Lusófona de Humanidades e Tecnologias

109 PUBLICATIONS 961 CITATIONS

SEE PROFILE

Some of the authors of this publication are also working on these related projects:

Clinical Psychology and Psychotherapy View project

Project Neuropsychology and Cognitive Sciences View project
Paulo Jorge Ferreira Lopes

Universidade Lusófona de Humanidades e Tecnologias

63 PUBLICATIONS 471 CITATIONS

SEE PROFILE

Giulia Campaioli

University of Padova

2 PUBLICATIONS 10 CITATIONS

SEE PROFILE 


\title{
Psychometric and Rash Analysis of the UCLA Loneliness Scale-16 in a Portuguese Sample of Older Adults
}

\author{
Bruno Faustino $^{1,2}$ (1) $\cdot$ Paulo Lopes $^{1} \cdot$ Jorge Oliveira $^{1} \cdot$ Giulia Campaioli $^{1}$ • \\ Maria Rondinone $^{1} \cdot$ Helena Bomfim ${ }^{1} \cdot$ Lindanuza Germano $^{1}$
}

Received: 1 October 2018/ Accepted: 9 April 2019

(C) National Academy of Psychology (NAOP) India 2019

\begin{abstract}
Loneliness is a serious concern in modern societies, particularly among older adults, while being imperative that clinicians use reliable instruments for an accurate assessment of this problem. This study aims to describe a mixed statistical approach to assess the psychometric properties of the UCLA Loneliness Scale-16 in Portuguese old-aged individuals. The sample comprised 153 individuals $(59.1 \%$ women and $40.3 \%$ men), aged $61-98$ $(M=78.80, S D=8.58)$. The psychometric properties of UCLA Loneliness Scale-16 were analyzed with exploratory factorial analysis, internal consistency, convergent and divergent validity and through the item response theory.
\end{abstract}

The work presented in this manuscript was the result of an original research.

Bruno Faustino

brunofaustino.psicologia@gmail.com

Paulo Lopes

paulo.jorge@ulusofona.pt

Jorge Oliveira

jorge.oliveira@ulusofona.pt

Giulia Campaioli

giulia.campaioli@gmail.com

Maria Rondinone

mariachiara.rondinone@gmail.com

Helena Bomfim

lenabomfim14@hotmail.com

Lindanuza Germano

lindagermanosoares@gmail.com

1 Faculdade de Psicologia e Ciências da Vida, Universidade Lusófona de Humanidades e Tecnologias, Campo Grande, 376, 1749-024 Lisbon, Portugal

2 Faculdade de Psicologia, Universidade de Lisboa, Lisbon, Portugal
The results suggested a bidimensional structure for this instrument. The scale showed satisfactory psychometric properties with a high internal consistency. In addition, a negative relationship with constructs of social support and functionality was also observed. Overall results suggest that the UCLA Loneliness Scale-16 is a psychometric reliable measure to evaluate social loneliness in the Portuguese elderly population.

Keywords Loneliness scale - Psychometrics · Rash analysis · Older adults

\section{Introduction}

Previous research showed a consistent increase in population aging, associated with increased life expectancy, with varying effects on the different countries mainly of Western societies (Freitas, Simões, Alves, \& Santana, 2011; Freitas, Alves, Simões, \& Santana, 2013), in which Portugal is no exception (Sousa, Rodrigues, Gregório, Branco, Gouveia, Canhão, \& Dias, 2017). According to data from the National Statistics Institute (INE, 2017), the Portuguese elderly population in 2016 comprised $20.4 \%$ of the national population, and estimates indicate that this number could increase up to $37.3 \%$ by 2080 , with 100 elderly people for every 150 people of working age (INE, 2017). As age increases, a set of associated problems also arise, like depression, anxiety, loss of functionality, lack of perceived social support, which leads to loneliness (Gerino, Rollè, Sechi, \& Brustia, 2017; Neto, 2014; Sousa et al., 2017).

Loneliness is a complex construct and has pervasive and detrimental effects on mental health and well-being (Gerino, et al., 2017; Rokach \& Neto, 2005), being conceptualized under different perspectives. Loneliness may be a 
mental state easier to describe than to define (Pocinho, Farate, \& Dias, 2010).

A common factor in each definition of loneliness is the perceived deficit in social relationships (Neto, 2014). Asher and Paquette (2003) referred to loneliness as the cognitive awareness of deficits on social and personal relationships, with enduring unpleasant affective reactions of sadness, emptiness and logging. Weiss (1973) defines loneliness as a dysphoric mood feeling associated with a perceived discrepancy between desired and real social relationships. Gale, Westbury, and Cooper (2018) stated that loneliness is a subjective feeling of disappointment with interpersonal relationships, usually associated with social isolation. One possible integrative definition for loneliness refers to it as a dysphoric affective state associated with dysfunctional cognitions, adverse life circumstances, poor problemsolving skills and dysfunctional social interactions (Poucinho, Farate, \& Dias, 2010). The pervasive problem of loneliness along with aging may be due to widowhood, frailty, lack of social interactions, decreasing health and institutionalization (Chen, Hicks, \& While, 2003; Gale et al., 2018; Neto, 2014). Also, caring for a dependent elderly person presupposes an emotional involvement, the physical effort and an expense of time and energy, which can cause high costs to the caregiver, leading to withdraw (Sousa, Figueiredo, \& Cerqueira, 2006). Moreover, loneliness may be a consequence of a diversity of factors, from present and past situations, which increases the complexity of this phenomenon (Russell, Peplau, \& Ferguson, 1978; Weiss, 1973). As such, loneliness may be a multifactorial construct with different aspects. Reliable and valid measures for assessing of loneliness are thus needed.

The seminal publication made by Weiss (1973) opened a field of research based on the study of loneliness. The revised UCLA Loneliness Scale (R-UCLA; Russel, Peplau, $\&$ Cutrona, 1980) became one of the widely used measures to assess feelings of loneliness, with satisfactory psychometric properties (Neto, 2014). This scale was translated and adapted to the Portuguese population by Neto (1989), demonstrating satisfactory psychometric properties.

Several versions of the UCLA scale were developed, with the concern of reducing the size and time of application. Russel and Cutrona (ULS-four items, 1980), Hays and DiMatteo (ULS-eight items, 1987) and Neto (ULS-six items, 1992) developed shorter forms that compared to longer forms showed adequate reliability and validity (Neto, 2014). Russel (1996) developed the UCLA Loneliness Scale (version 3), with ten items based on corrected item-total correlations. In Portugal, the ULS- 6 had been studied with adolescents (Neto, 1992, 2002), college students (Neto, 2006) and older adults (Neto, 2014).

Furthermore, Pocinho et al. (2010) developed a version of the UCLA based on the work of Russel et al. (1978) and studied their psychometric properties in a Portuguese sample of older adults. Through exploratory factor analysis (EFA), they found a two-factor solution model, with 16 items. The two factors were social isolation and affinities while suggesting satisfactory internal consistency through Cronbach's alpha for this two-factor model with 0.867 and 0.806 , respectively. The authors suggested that ULS-16 was a valid and precise measure for assessing loneliness in older adults. Despite these conclusions, further studies are needed to establish the ULS-16 as a reliable and valid instrument to assess loneliness in the older population while providing psychometric robustness for this instrument. The existing literature regarding the psychometric studies of ULS-16 in older adults is mainly based on classical measurement theory, neglecting the difficulty of scale items and the underlying characteristics of each individual, which are the key assumptions of the item response theory. In this sense, the current paper aims to contribute to the validation of the ULS16 in the Portuguese population by combining the classical measurement theory methods (CMT) with the Rasch Model (RM) based on the item response theory. Linacre (2002) stated the RM as a procedure that could optimize surveys by increasing the internal validity by studying not only the individuals but also the difficulty of the items for the subjects.

This study describes an innovative statistical approach to the study of this ULS- 16 by combining the advantages of both these statistical approaches. The psychometric properties were determined using EFA, Cronbach's alpha, and Rasch analysis. Moreover, convergent and divergent validity was examined with two related constructs, namely social support and functionality.

\section{Method}

\section{Participants}

The sample for this study comprised 154 participants (91 female, $59.1 \%$ ) that were recruited in the community from elder institutions in Lisbon area of Portugal. Ages ranged from 61 to 98 , with a mean age of $78.80(S D=8.58)$. Regarding education, $3.2 \%$ were illiterate, $64.3 \%$ had primary education, $13 \%$ had secondary education, $11 \%$ had tertiary education, and $5.8 \%$ had a superior education. Concerning marital status, $5.2 \%$ were single, $33.1 \%$ were married, $8.4 \%$ were divorced, and $52.6 \%$ were widowed. As for the number of family members, $85.4 \%$ reported having sons and $14.3 \%$ not having sons.

\section{Measures}

Participants were assessed with three valid self-report scales to the Portuguese population, described below, along 
with sociodemographic questions related to age, gender, education, marital status, and the number of family members.

UCLA Loneliness Scale (ULS-16) by Russel (1996), Portuguese version of Pocinho et al. (2010), was used to measure loneliness. This version of UCLA is composed by 16 items, divided into two factors, social isolation and affinity. Items describe subjective feelings of loneliness and are scored on a Likert scale of 1 (never) to 4 (often). Higher scores indicate greater loneliness. The Cronbach's alpha coefficient in this study was 0.930 for overall scale, 0.920 for social isolation subscale and 0.834 for affinity subscale.

Multidimensional Scale of Perceived Social Support (MSPSS) by Zimet, Dahlem, Zimet, and Farley (1988), Portuguese version by Carvalho, Gouveia, Pimentel, Maia, and Pereira (2011), with 12 items assessed in a Likert scale from 1 to 7 . This scale has three subscales, each one addressing a different source of social support: family, friends, and significant other. Cronbach's alphas in the current study were $0.935,0.925$ and 0.868 , respectively.

The Lawton Brody Instrumental Activities of Daily Living (IADL) by Lawton and Brody (1969), Portuguese version by Araújo, Pais-Ribeiro, Oliveira, Pinto, and Martins (2008), is an instrument to assess functionality in everyday living activities, such as using the telephone, shopping, food preparation, among others. The score varies between 0 (low functioning, dependent) and 8 (high functioning, independent) for women, and 0-5 for men. The Cronbach's alpha in the present study was 0.926 .

Practitioner Assessment of Network Type (PANT) by Wenger (1991), translation to Portuguese by Brito, Gamito, Oliveira, and Morais (unpublished), is an eight-item scale that assessed the distance between one person and his relative/child/sibling (three items; 5-point scale ranging from less than $1 \mathrm{~km}$ to more than $50 \mathrm{~km}$, alpha =0.464); frequency of interaction with relatives/friends/neighbors (three items; 6-point scale ranging from daily to never, alpha $=0.652$ ), and engagement in community/religious activities (two items; 3-point scale ranging from never to regularly, alpha $=0.592$ ).

\section{Procedures}

Participants were recruited and assessed by undergraduate master degree students in the Lisbon area of Portugal, mostly in day centers and institutions. Informed consent forms were made available to the institutions and to each participant. Data collection was conducted in quiet rooms. Completion of protocols was the responsibility of the technicians, who read the questions aloud individually to each participant. Completion of the three questionnaires usually required no more than $30 \mathrm{~min}$. This research was made within current legal and ethical norms in Portugal. This study was approved by an ethics committee of the host institution of this study. There were no financial fees paid to volunteers.

\section{Data Analysis}

\section{Classical Measurement Theory}

Reliability and validity procedures were used in the study. EFA was done to explore the factorial structure of ULS-16. Internal consistency was assessed with Cronbach's alpha and inter-item correlations. Frequencies, percentages, ranges, means, and standards deviations were conducted for data description. Pearson product-moment correlation coefficient was used to test convergent and divergent validity between ULS-16 and social support (MSPSS), functionality (IADL), and proximity (PANT) scales. Discriminant validity was tested using the analysis of variance (ANOVA). Statistical analysis was performed in IBM SPSS Statistics version 24.

\section{Rasch Model}

The rating scale model (RSM) is used for polytomous items, because this model transforms the ordinal response scale from participants on an interval scale (Andrich, 1988). This procedure allows conjoint measurement of persons and items responses (i.e., parameters for persons and items are given in the same units), and it is recommended for testing psychological assessment instruments (Wright \& Mok, 2004; Wilson, 2005). The RSM was conducted using the software Winsteps (v3.92.1) for Windows ${ }^{\circledR}$.

\section{Results}

\section{Construct Validity}

EFA was run on raw data of ULS-16. We used the maximum likelihood method with Promax-rotated solution, but before the correlated matrix was analyzed for an adequate model fit. The value of the Kaiser-Meyer-Olkin was 0.909 $(<.60)$ and a significant Bartlett coefficient $\left(X^{2}=1408.26\right.$, $p=0.001$ ), was found. EFA suggested a two-factor solution model explaining $57.51 \%$ of the variance. This factorial structure is aligned with the study of Pocinho et al. (2010) that suggested two factors that resemble social isolation and affinity factors (Table 1). 
Table 1 Matrix-rotated solution with two factors of UCLA-16 scale

\begin{tabular}{|c|c|c|}
\hline & \multicolumn{2}{|l|}{ Factor } \\
\hline & 1 & 2 \\
\hline 13-I feel isolated from other people & 0.850 & \\
\hline 5-I feel that I have no one to turn to & 0.844 & \\
\hline 16-I feel excluded form other people & 0.821 & \\
\hline 4-It feels like no one really understands me & 0.702 & \\
\hline 12-I think that no one really knows & 0.681 & \\
\hline 8-I feel abandoned & 0.643 & \\
\hline $15-$ It is hard to do friends & 0.599 & \\
\hline 6-I do not feel intimate with anyone & 0.566 & \\
\hline $\begin{array}{l}\text { 7-It feels that those around me no longer share my } \\
\text { interests }\end{array}$ & 0.563 & \\
\hline 9-I feel completely alone & 0.540 & \\
\hline $\begin{array}{l}\text { 10-I am unable to establish contacts and } \\
\text { communicate with those around me }\end{array}$ & 0.534 & \\
\hline 14-I feel unhappy and distant from others & 0.512 & \\
\hline 3-I feel lack company & & 0.971 \\
\hline 1-I am feeling unhappy to do many things alone & & 0.711 \\
\hline 2-I feel that I do not have someone to talk to & & 0.681 \\
\hline $11-$ My social relationships are superficial & & 0.470 \\
\hline
\end{tabular}

$M$ Mean, $S D$ standard deviation, Item separation reliability, $P S R$ Pearson separation reliability

\section{Rash Analysis}

According to the guidelines for scales optimization (Linacre, 2002), as observed in Supplementary 1, all values of the ULS-16 subscales are oriented with the latent variable. On the other hand, in the observations, all the categories show more than ten observations and that, in general, the distributions are symmetric and adequate. According to the third guideline, we found a monotonic increase in the means of the people who choose the categories, while in the fourth guideline, all values are adequate that suggest good fit. In view of the monotonic increase in the calibration steps, we also found that the values are satisfactory. On the other hand, the coherence level also shows quite adequate values between $\mathrm{M} \rightarrow \mathrm{C}$ and $\mathrm{C} \rightarrow \mathrm{M}$. As for the last two guidelines, all values are greater than 1.4 and less than 5.0, again with satisfactory scores (Fig. 1).

In Supplementary data 2, it is possible to observe a joint representation of people and items, with the items presenting a distribution in the interval between -1 and +1 loggits and people between -4 and +4 loggits. In summary, these results suggest that the data are adequate in all the guidelines proposed by Linacre (2002), with a good general functioning of the ULS-16, i.e., the scale may have useful and effective psychometric properties in the evaluation of loneliness.
Regarding the adjustment of the data to the Rasch Model and taking into account the indexes shown in Table 2, outfit values within the productive limits are depicted, either for items $(M=0.00 ; S D=0.13)$ or for people $(M=-1004$; $S D=0.45)$ in social isolation subscale and either for items $(M=0.00 ; S D=0.13)$ or for people $(M=-0.27, S D=$ 0.72 ) in affinities subscale, indicating that the adjustment is adequate and according to the expected standard, i.e., 1.00, adequate values to carry out a productive measurement (Linacre, 2002). At the level of precision, adequate values were found for both subscales, namely: social isolation scale: item separation reliability (0.91), Pearson separation reliability (0.78), and Cronbach's alpha (0.92); affinities scale: item separation reliability (0.76), Pearson separation reliability (0.67) and Cronbach's alpha (0.82). The low percentage of people with high imbalance (social isolation, $5.2 \%$ and affinities, $13 \%$ ) suggests also that the values are adequate in this sample.

\section{Internal Consistency}

According to the two-factor structure found in EFA, Cronbach's alpha and inter-item correlation were calculated. Total scale Cronbach's alpha was 0.930, with corrected item-total correlations ranging from 0.51 to 0.73 . In the factor "social isolation", the Cronbach's alpha was 0.920 , with corrected item-total correlations ranging from 0.56 to 0.76 . In the factor "affinities", Cronbach's alpha was 0.824 , with corrected item-total correlations ranging from 0.54 to 0.74 . All Cronbach's alphas suggested good internal consistency (Urbina, 2004)—see Table 3.

\section{Convergent, Divergent and Discriminant Validity}

Evidence for convergent validity is given by a relationship between two constructs that are theoretically related (Urbina, 2004). In this sense, we expected that loneliness (ULS-16) would be negatively associated with social support (MSPSS). The results presented in Table 3 show a significant negative correlation between ULS-16 and MSPSS scales $(p<0.001)$, which may provide evidence for the convergent validity of the ULS-16.

In contrast, evidence for divergent validity is given by the absence of a relationship between two constructs that are not theoretically related (Urbina, 2004). Thus, we expected that loneliness (ULS-16) did not correlate with functionality (IADL), because there is no clear evidence that loneliness affects functionality. The results presented in Table 3 show that there are no significant correlations between the ULS-16 subscales with IADL $(p<0.001)$, which may provide for divergent validity of the ULS-16.

Discriminating validity is related to the discriminant properties in which a construct is able to differentiate 

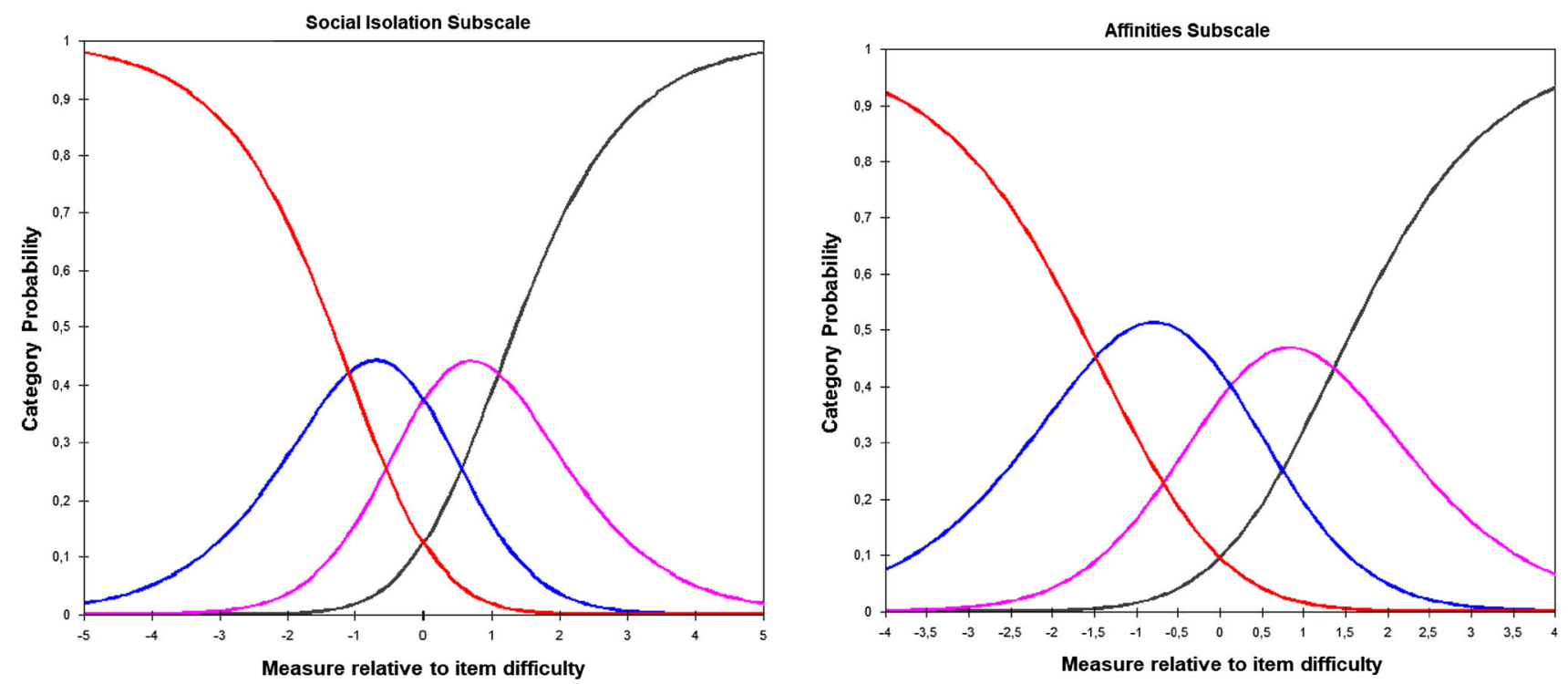

Fig. 1 Overall fit model

Table 2 Rating scale model statistics

\begin{tabular}{lll}
\hline & Social isolation & Affinities \\
\hline & $M(\mathrm{SD})$ & $M(\mathrm{SD})$ \\
Item outfit & $0.00(0.13)$ & $0.00(0.13)$ \\
Person outfit & $-1.04(0.45)$ & $-0.27(0.72)$ \\
TRI-Item separation reliability & 0.91 & 0.76 \\
TRI-Person separation reliability & 0.78 & 0.67 \\
TRI-Cronbach's $\alpha$ & 0.92 & 0.82 \\
$\%$ items with outfit $>2$ (no. 1) & $0 \%$ & $0 \%$ \\
$\%$ persons with outfit $>2$ & $5.2 \%$ & $13 \%$ \\
\hline
\end{tabular}

between different groups/conditions (Urbina, 2004). We expected that the ANOVA would differentiate individuals in social isolation subscale (PANT) regarding the frequency of interactions with relatives/friends/neighbors as a factor. By using this variable, our intent was to understand whether the ULS-16 would differentiate between individuals with higher vs. lower social isolation according to this instrument (PANT). The ANOVA showed significant differences between these groups $(F(1,152)=1.88$, $p<0.029$ ). These results may provide evidence for discriminant validity (Table 4 ).

\section{Discussion}

This paper intends to provide evidence for good psychometric properties of the ULS-16 according to the classical test theory and the item response theory (Rasch Model) by studying a sample of Portuguese older adults. The factor structure was studied with Rasch analysis, reliability, and validity for construct, convergent, divergent, and discriminant validity. This is the first study to combine two different psychometric procedures as classical measurement theory and the item response theory (Rasch Model) to study the ULS-16.

This analysis started with the EFA determine to construct validity for the ULS-16. A two-factor solution was found which represent two facets of loneliness: social isolation and affinities. These results are aligned with previous findings of Pocinho et al. (2010). In our study, three items $(4,9$, and 11) had changed between subscales when compared to the results of the previous study. Through a careful reading of item 9 "Sente-se completamente só?" (Do you feel completely alone?) was verified that matched the social isolation subscale, whereas items 4 "Sente-se como se ninguém o compreendesse?" (Do you feel like no one understands you?) and 11 "As suas relações sociais são superficiais?" (Are your social relationships superficial?), matched the affinities' subscale. These differences may be related to different characteristics of the sample used in the study of Pocinho et al. (2010).

ULS-16 was also tested using Rasch analysis. The original four-category response was adequate according to the Linacre (2002) guidelines. In this sense, we recommend using this system in future ULS-16 applications. The total score of ULS-16 and the two subscales showed good internal consistency supported also with the Rasch analysis. No items with severe misfit were found and essential bidimensionality was empirically supported.

Furthermore, validity was also tested for convergent, divergent, and discriminant validity. The negative 
Table 3 Itemwise reliability of UCLA-16

\begin{tabular}{|c|c|c|c|c|c|c|}
\hline \multicolumn{3}{|c|}{ Total scale } & \multicolumn{2}{|l|}{ Social isolation subscale } & \multicolumn{2}{|l|}{ Affinities subscale } \\
\hline & Corrected item correlation & Alfas & Corrected item correlation & Alfas & Corrected item correlation & Alfas \\
\hline 1 & 0.515 & 0.929 & & & 0.598 & 0.800 \\
\hline 2 & 0.688 & 0.924 & & & 0.723 & 0.751 \\
\hline 3 & 0.662 & 0.925 & & & 0.747 & 0.729 \\
\hline 4 & 0.732 & 0.923 & 0.747 & 0.91 & & \\
\hline 5 & 0.721 & 0.924 & 0.756 & 0.91 & & \\
\hline 6 & 0.601 & 0.926 & 0.608 & 0.916 & & \\
\hline 7 & 0.656 & 0.925 & 0.651 & 0.914 & & \\
\hline 8 & 0.670 & 0.925 & 0.672 & 0.913 & & \\
\hline 9 & 0.676 & 0.924 & 0.657 & 0.914 & & \\
\hline 10 & 0.563 & 0.927 & 0.565 & 0.918 & & \\
\hline 11 & 0.590 & 0.927 & & & 0.546 & 0.824 \\
\hline 12 & 0.687 & 0.924 & 0.69 & 0.912 & & \\
\hline 13 & 0.732 & 0.923 & 0.76 & 0.91 & & \\
\hline 14 & 0.675 & 0.924 & 0.651 & 0.914 & & \\
\hline 15 & 0.641 & 0.925 & 0.644 & 0.914 & & \\
\hline 16 & 0.604 & 0.926 & 0.648 & 0.914 & & \\
\hline \multicolumn{2}{|c|}{ Total alfas } & 0.930 & & 0.920 & & 0.824 \\
\hline
\end{tabular}

Table 4 Pearson correlations between UCLA-16, MSPSS and PANT $(N=154)$

\begin{tabular}{llllr}
\hline & MSPSS (Family) & MSPSS (Friends) & MSPSS (Others) & IADL \\
\hline UCLA-Social isolation & $-0.473^{* *}$ & $-0.353^{* *}$ & $-0.480^{* *}$ & -0.083 \\
UCLA-Affinities & $-0.313^{* *}$ & $-0.439^{* *}$ & $-0.309^{* *}$ & 0.026 \\
\hline
\end{tabular}

Legend Multidimensional scale of perceived social support (MSPSS), Instrumental activities of daily living (IADL) $* * p<0.01$

associations between ULS-16 social isolation and affinities subscales with social support through the MSPSS subscales of family, friends, and others matched theory prediction: Higher social support has a mediator effect lowering social isolation (Mendieta, Martín, \& Jacinto, 2012). Evidence for divergent validity was showed through the absence of associations between the ULS-16 subscales with functionality (IADL).

As regards to discriminant validity, the analysis was conducted to understand whether the ULS-16 differentiate individuals with higher versus lower social isolation, according to one item of the PANT (frequency of interactions subscale from PANT). The prediction was that perceived social isolation may change within the frequency of interactions, which was confirmed in the current study. Loneliness and social isolation are extremely associated and may be mediated by the perceptions of interactions with others (Liu \& Floud, 2017).

ULS-16 is a loneliness self-report measure widely used in Portugal and abroad (Gale et al., 2018; Neto, 2014), but no studies on the ULS-16 were found with Rasch analysis. Linacre (2002) stressed the importance of using Rasch analysis to improve validation procedures, by studying both persons and items in psychometric instruments. Moreover, loneliness in older adults may be a result of different life issues, which increases it's complexity (Russell, Peplau, \& Ferguson, 1978; Weiss, 1973). In this sense, reliable measures may help clinicians to accuratly asses loneliness and it's precipitant factors.

However, there are also some limitations to these results. Firstly, one important step to improve reliability was not accomplished in this study-test-retest procedure-which was not performed due to time constraints and did not allow to assess the temporal stability of this instrument. Secondly, measures to overcome biases from self-reports were not applied, for example, the use of behavioral rating scales conducted by independent observers. Another issue is related to the diverse samples of different settings used in our study, such as community or care centers, which may confound these results. Despite these limitations, this study expanded the validation procedures by combing the classic test theory and the item response theory.

In sum, the ULS-16 seems to be a valid scale to assess loneliness in older adults. This study has shown evidence for good psychometric properties of the ULS-16. Adequate 
and satisfactory indexes of validity (two-factor structure, convergent, divergent, and discriminant validity) are provided along with reliability criteria (internal consistency). These results were supported by the Rasch Model, which concur with a two-solution factorial structure. This study can be useful for both clinicians and researchers to develop new interventions targeting loneliness and social isolation by using valid and reliable measure of loneliness.

\section{References}

Andrich, D. (1988). Rasch models for measurement. London: Sage. Araújo, F., Pais-Ribeiro, J., Oliveira, A., Pinto, C., \& Martins, T. (2008). Validação da escala de Lawton e Brody numa amostra de idosos não institucionalizados. In I. Leal., J. Pais Ribeiro., I. Silva., \& S. Marques (Eds.), Actas do $7^{\circ}$ congresso nacional de psicologia da saúde (pp. 217-220). Lisboa: ISPA (The validation of the Lawton and Brody scale in a sample of noninstitutionalized elderly).

Asher, S. R., \& Paquette, J. A. (2003). Loneliness and peer relations in childhood. Current Directions in Psychological Science, 12, 75-78. https://doi.org/10.1111/1467-8721.01233.

Brito, R., Gamito, P., Oliveira, J., \& Morais, D. (unpublished). Portuguese version of Practitioner Assessment of Network Type (PANT).

Carvalho, S., Gouveia, J., Pimentel, O., Maia, D., \& Pereira, J. (2011). Caracteristicas psicométricas da versão portuguesa da escala multidimensional de suporte social percebido (Multidimensional scale of perceived social support-MSPP). Psychologica, 54, 338-348. (Psychometric characteristics of the Portuguese version of the Multidimensional Scale of Perceived Social Support).

Chen, Y., Hicks, A., \& While, A. E. (2003). Loneliness and social support of older people in China: A systematic literature review. Health and Social Care Community, 22(2), 113-123. https://doi.org/10.1111/hsc.12051.

Freitas, S., Alves, L., Simões, M. R., \& Santana, I. (2013). Importância do rastreio cognitivo na população idosa. Revista E-Psi, 3(1), 4-24. (Importance of cognitive screening in the elderly population).

Freitas, S., Simões, M. R., Alves, L., \& Santana, I. (2011). Montreal cognitive assessment (MoCA): Normative study for the Portuguese population. Journal of Clinical and Experimental Neuropsychology, 33(9), 989-996.

Gale, C. R., Westbury, L., \& Cooper, C. (2018). Social isolation and loneliness as risk factors for the progression of frailty: the english longitudinal study of aging. Age and Ageing, 3, 392-397.

Gerino, E., Rollè, L., Sechi, C., \& Brustia, P. (2017). Loneliness, resilience, mental health, and quality of life in old age: A structural equation model. Frontiers of Psychology, 8, 1-12.

Hays, R. D., \& DiMatteo, M. R. (1987). A short-form measure of loneliness. Journal of Personality Assessment, 51, 69-81.

Instituto Nacional de Estatística. (2017). Projeções de População Residente 2015-2080. Destaque - informação à comunidade social, (pp. 1-19). https://www.ine.pt/xportal/xmain?xpid=INE\& xpgid=ine_destaques\&DESTAQUESdest_boui=277695619\&DE STAQUESmodo $=2 \&$ xlang $=$ pt. $\quad$ (Projections of Resident Population).

Lawton, M. P., \& Brody, E. M. (1969). Assessment of older people: Self-maintaining and instrumental activities of daily living. Gerontologist, 9, 179-186.
Linacre, J. M. (2002). Optimizing rating scale category effectiveness. Journal of Applied Measurement, 3(1), 85-106.

Liu, B., \& Floud, S. (2017). Unraveling the associations between social isolation, loneliness, and mortality. The Lancet, 2(6), 248-249.

Mendieta, I. H., Martin, M. A., \& Jacinto, L. G. (2012). The relationship between social support, loneliness, and subjective well-being in a spanish sample from a multidimensional perspective. Social Indicators Research, 114, 1013-1034. https://doi.org/10.1007/s11205-012-0187-5.

Neto, F. (1989). Avaliacão da solidão. Psicologia Clínica, 2, 65-79. (Assessment of solitude).

Neto, F. (1992). Loneliness among Portuguese adolescents. Social Behavior Personality, 20, 15-22.

Neto, F. (2002). Loneliness and acculturation among adolescents from immigrant families in Portugal. Journal of Applied Social Psychology, 32, 630-647.

Neto, F. (2006). Dimensions and correlates of social axioms among a Portuguese sample. Individual Differences Research, 4, $340-351$.

Neto, F. (2014). Psychometric analysis of the UCLA loneliness scale (ULS-6) in older adults. Europe Journal of Ageing. https://doi.org/10.1007/s10433-014-0312-1.

Pocinho, M., Farate, C., \& Dias, A. D. (2010). Validacão psicométrica da escala UCLA-Loneliness para Idosos Portugueses. Interações, 18, 65-77. (Psychological validation of the UCLA scale-loneliness for Portuguese elderly).

Rokach, A., \& Neto, F. (2005). Age, culture, and the antecedents of loneliness. Social Behavior Personality, 33, 477-494.

Russell, D. (1996). The UCLA loneliness scale (Version 3): Reliability, validity, and fator structure. Journal of Personality Assessment, 66, 20-40.

Russell, D., Peplau, L., \& Cutrona, C. (1980). The revised UCLA loneliness scale: concurrent and discriminate validity evidence. Journal of Personality and Social Psychology, 39, 472-480.

Russell, D., Peplau, L., \& Ferguson, M. (1978). Developing a measure of loneliness. Journal of Personality Assessment, 42, 290-294.

Sousa, L., Figueiredo, D., \& Cerqueira, M. (2006). Envelhecer em Família. Porto: Âmbar. (Aging in Family).

Sousa, R. D., Rodrigues, A. M., Gregório, M. J., Branco, J. C., Gouveia, M. J., Canhão, H., \& Dias. S. S. (2017). Anxiety and depression in the Portuguese older adults: Prevalence and associated factors. Frontiers in Medicine, 4, 196. https://doi.org/ 10.3389/fmed.2017.00196

Urbina, S. (2004). Essentials of behavioral science series. Essentials of psychological testing. Hoboken: Wiley.

Weiss, R. S. (1973). Loneliness: The experience of emotional and social isolation. Cambridge, MA, US: The MIT Press.

Wenger, G. C. (1991). A network typology: From theory to practice. Journal of Aging Studies, 5, 147-162. https://doi.org/ 10.1016/0890-4065(91)90003-B.

Wilson, M. (2005). Constructing measures. Mahwah: LEA.

Wright, B. D. \& Mok, M. (2004). An overview of the family of Rasch measurement models. In E. V. Smith \& R. M. Smith (Eds.), Introduction to Rasch measurement. JAM Press, Maple Grove.

Zimet, G. D., Dahlem, N., Zimet, S., \& Farley, G. (1988). The multidimensional scale of perceived social support. Journal of Personality Assessment, 52, 610-617.

Publisher's Note Springer Nature remains neutral with regard to jurisdictional claims in published maps and institutional affiliations. 